\title{
LA DISCRIMINACIÓN RACIAL Y ÉTNICA EN LA JURISPRUDENCIA DEL TRIBUNAL EUROPEO DE DERECHOS HUMANOS
}

\author{
FERNANDO REY MARTÍNEZ *
}

\begin{abstract}
RESUMO: Neste ensaio, o autor conclui pela baixa densidade de proteção da Corte Européia de Direitos Humanos sobre a discriminação étnica, especialmente, examina o retrocesso ocorrido com a Decisão proferida no caso Ostrova.

PALAVRAS-CHAVE: Tutela Jurisdicional, Direitos Humanos, Discriminação Étnica.
\end{abstract}

\begin{abstract}
In this essay the author infers the weak density of protection provided by The European Court of Human Rights in ethnic discrimination and specially examines the retrocession produced by the pronounced Judgment in the Ostrova case.
\end{abstract}

KEYWORDS: Jurisdictional Protection Procedure, Human Rights, Ethnic Discrimination.

\begin{abstract}
SUMARIO: 1. LA PROHIBICIÓN DE DISCRIMINACIÓN EN EL TRIBUNAL DE ESTRASBURGO: UN DERECHO “DE BAJA INTENSIDAD”. II. LA JURISPRUDENCIA ANTERIOR A LA SENTENCIA D.H. Y OTROS CONTRA LA REPÚBLICA CHECA, DE 7 DE FEBRERO DE 2.006. a) Introducción: los escenarios de conflicto. b) Agresiones racistas por agentes de la autoridad. c) Agresiones racistas vecinales y deficiente tutela judicial posterior. d) Expulsión de caravanas. e) Discriminación en frontera. f) Discriminación racial e imparcialidad judicial en juicio por jurados. g) Discurso racista y libertad de información. III. ANÁLISIS DEL CASO OSTRAVA. a) Los argumentos del Tribunal. b) Voto concurrente del Juez Costa. c) Opinión discrepante del Juez Cabral Barreto. d) Comentario crítico de la Sentencia: ¿es la exhumación de la doctrina Plessy, "separados, pero iguales”? IV. CONCLUSIÓN: LA DISCRIMINACIÓN RACIAL, UN DERECHO RECONOCIDO ESCASAMENTE Y CON RETROCESOS POR EL TRIBUNAL EUROPEO DE DERECHOS HUMANOS.
\end{abstract}

\section{LA PROHIBICIÓN DE DISCRIMINACIÓN EN EL TRIBUNAL DE ESTRASBURGO: UN DERECHO “DE BAJA INTENSIDAD”}

La Sentencia del Tribunal Europeo de Derechos Humanos D.H. y otros contra la República Checa, de 7 de febrero de 2.006, que tuvo un notable impacto mediático en su momento ${ }^{1}$, ha resuelto de modo discutible un asunto de discriminación racial

\footnotetext{
* Doctor en Derecho por la Universidad de Valladolid.

${ }^{1}$ Incluso el New York Times le dedicó un editorial (11 de marzo de 2.006). Según este periódico, “a pesar de todas las dificultades a la que se tienen que enfrentar los musulmanes, el grupo que sufre más abusos en Europa sigue siendo, y con diferencia, el de los gitanos". El editorialista se muestra muy crítico con la Sentencia (recordando, de paso, que "la mayoría del Tribunal está compuesta principalmente por representantes de países del Este") y le pide al Tribunal que aprenda la lección dada por Estados Unidos: "Hace algunas
} 
en relación con el derecho a la educación de dieciocho niños gitanos. En efecto, el Tribunal no ha considerado contrario al art. 14 del Convenio ${ }^{2}$ el envío de estos niños a colegios especiales para discapacitados mentales sin perspectiva educativa alguna (práctica sistemática allí, puesto que el 75\% de los niños gitanos van a este tipo de centros, según datos aportados por el propio gobierno checo).

La Sentencia es interesante no sólo porque remite a un nuevo escenario de conflicto de discriminación racial no planteado hasta el momento por el Tribunal Europeo, el del acceso a la educación, sino también porque, a diferencia de los ámbitos anteriores, casi todos ellos, como veremos, ligados a actos de violencia (pública o privada) contra miembros de minorías étnicas (casi siempre gitana), y, por tanto, patentes discriminaciones directas, en este caso se abría al Tribunal la posibilidad de ampliar la protección contra las discriminaciones raciales acogiendo por primera vez la categoría de las discriminaciones indirectas, ya sólidamente establecida en suelo europeo, por lo demás ${ }^{3}$. Pero el Tribunal ha desaprovechado la oportunidad. Esto no es sorprendente porque su aproximación al concepto de prohibición de discriminación en general del art. 14 del Convenio y a la racial en particular había sido hasta el momento, aún reconociendo algunos avances ${ }^{4}$, más bien rutinaria, contenida, formalista y con tendencia a ser race-blind, esto es, indiferente al factor racial. La igualdad entre grupos étnicos no parece estar entre los núcleos principales de interés del Tribunal, cuya jurisprudencia en este punto es llamativamente pobre desde un punto de vista técnico. La cabal justificación de tales afirmaciones nos llevará, en primer lugar, al análisis de la interpretación habitual que hace el Tribunal de la cláusula anti-discriminatoria del art. 14 del Convenio y, más tarde, al examen crítico de la jurisprudencia sobre discriminaciones raciales, deteniéndonos particularmente en la Sentencia D.H. y otros contra la República Checa (también conocida como “caso Ostrava”).

décadas, Estados Unidos aprendió, mediante un doloroso proceso, que las políticas gubernamentales y las actitudes sociales podían ser cómplices de que se mantuviera en la misma situación a una clase sometida y que la discriminación podía existir a pesar de que las leyes parecieran justas. Europa no ha aprendido la lección. Desde hace ya un tiempo, el Tribunal Europeo de Derechos Humanos se viene mostrando reacio a prohibir prácticas discriminatorias en ausencia de pruebas de la intención de discriminar, permitiendo así que la discriminación se oculte bajo otro nombre. El Tribunal debería aprovechar la oportunidad para actualizar y revertir una decisión que ha dejado a las relaciones raciales europeas bastante atrasadas con respeto a la realidad que se vivía en Estados Unidos en 1.954”. El New York Times exagera, obviamente, porque el Tribunal de Estrasburgo no marca el estándar máximo de protección de los derechos en Europa, sino, justamente, el mínimo (y por ello no ostenta una posición equivalente a la del Tribunal Supremo Federal norteamericano). Pero acierta en su tesis de la "discriminación oculta”, que yo preferiría llamar más técnicamente "indirecta”. Sobre esto me remito a la argumentación del presente estudio.

2 "El goce de los derechos y libertades reconocidos en el presente Convenio ha de ser asegurado sin distinción alguna, especialmente por razones de sexo, raza, color, lengua, religión, opiniones políticas u otras, origen nacional o social, pertenencia a una minoría nacional, fortuna, nacimiento o cualquier otra situación”.

${ }^{3}$ Sobre todo tras la Directiva 2000/43/CE relativa a la aplicación del principio de igualdad de trato de las personas independientemente de su origen racial o étnico, de 29 de junio de 2.000. Un análisis de esta Directiva puede encontrarse en mi estudio: "La prohibición de discriminación racial o étnica en la Unión Europea y en España. El caso de la minoría gitana”, en la Revista de Derecho Político de la UNED n 57, Madrid 2.003, pp. 91-103.

${ }^{4}$ Particularmente destacable es el giro de tendencia que supuso la Sentencia Nachova y otros contra Bulgaria, de 6 de julio de 2.005 en relación con las agresiones racistas de agentes públicos. 
¿Cuál es, entonces, la lectura que, con carácter general, hace el Tribunal de la cláusula anti-discriminatoria del art. 14 del Convenio ${ }^{5}$ ?:

$1^{\circ}$ ) Discriminar es "tratar de modo diferente, sin una justificación objetiva y razonable, a personas situadas en situaciones sustancialmente similares”. La Sentencia que el Tribunal últimamente cita como leading-case de esta doctrina es Willis contra Reino Unido, de 11 de septiembre de $2.002^{6}$. En un célebre caso, Thlimmenos contra Grecia, de 6 de abril de 2.000, el Tribunal parece acoger también la denominada “discriminación por indiferenciación”, es decir, la existencia de discriminación cuando los Estados no traten de modo diferente, sin una justificación objetiva y razonable, a personas cuyas situaciones son sustancialmente distintas. Por tanto, habría discriminación cuando no se trata jurídicamente igual a los iguales, pero también cuando no se trata de modo distinto a los desigualmente situados. Sin embargo, esta última doctrina, que exigiría tratar jurídicamente mejor a cualquiera que, en una situación comparable, esté de hecho peor (y, por tanto, que consagraría un principio, por así decir, activo del Estado social y de la igualdad de oportunidades) no parece estar consolidada en el Tribunal, pues sólo la aplicó en el citado asunto Thlimmenos, yo creo que únicamente para alcanzar una solución justa en ese caso ${ }^{7}$. Más allá de él, no le aventuro un gran futuro.

$2^{\circ}$ ) Los Estados miembros disfrutan de "un cierto margen de apreciación” a la hora de valorar si, y con qué alcance, las diferencias en otras situaciones similares justifican una diferencia de trato, pero la decisión final sobre su conformidad con las exigencias que establece el Convenio pertenece al Tribunal Europeo de Derechos Humanos.

$3^{\circ}$ ) El art. 14 del Convenio no tiene existencia independiente, puesto que sólo puede ser alegado junto con otro de los derechos reconocidos en el Convenio; aunque no es necesario que el Tribunal estime una violación de éste para poder apreciar la existencia de discriminación (esto es, tiene una cierta autonomía que podríamos llamar de "segundo grado", una vez apreciada la vinculación de la prohibición de discriminación con cualquier otro derecho del Convenio). La aplicación del art. 14 es, además, "subsidiaria"” en relación con los demás derechos del Convenio porque si el Tribunal constata la vulneración de éstos, no es preciso que examine su lesión respecto de la prohibición de discriminación. El Tribunal afirma que el art. 14, aunque no tenga existencia independiente, “juega un importante papel complementario” del resto de derechos (Timishev contra Rusia, de 13 de diciembre de 2.005).

\footnotetext{
${ }^{5}$ Un magnífico estudio sobre el particular puede encontrarse en: Encarna Carmona, "La prohibición de discriminación (art. 14 CEDH y Protocolo 12)”, en La Europa de los Derechos. El Convenio Europeo de Derechos Humanos, (J. García Roca y P. Santolaya coords.), CEPC, Madrid, 2.005, pp. 665-695.

${ }^{6}$ Un asunto en el que el Tribunal estimó lesionado el derecho de propiedad privada (art. 1 del Protocolo Adicional Primero) en relación con la prohibición de discriminación por razón de sexo (art. 14) por el hecho de que las pensiones de viudedad se concedieran a las mujeres pero no a los varones.

${ }^{7}$ El asunto era bastante claro. Al señor Thlimmenos se le impedía legalmente el acceso a la función pública de censor jurado de cuentas porque había sido condenado penalmente con anterioridad; pero lo había sido porque, como testigo de Jehová, se había negado a llevar uniforme militar. El Tribunal sostiene que no hay justificación objetiva y razonable para no tratar al señor Thlimmenos de modo distinto al de otras personas condenadas por delito grave y, por tanto, habría violación del art. 14 del Convenio en relación con el derecho de libertad religiosa del art. 9.

${ }^{8}$ E. Roca, ob.cit., p. 693. Así lo viene expresando el Tribunal desde el caso Airey contra Irlanda, de 9 de octubre de 1.979 .
} 
Así, pues, en apretada síntesis, podríamos contraer la jurisprudencia del Tribunal de Estrasburgo sobre la prohibición de discriminación del art. 14 a la siguiente fórmula: discriminación como diferencia jurídica de trato no razonable/ aplicación amplia y muy generosa de la doctrina del margen estatal de apreciación/ y función complementaria del art. 14 .

No comparto en absoluto esta interpretación de la cláusula anti-discriminatoria del art. 14 del Convenio de Roma, que yo calificaría como “de baja intensidad”, aunque hay que reconocer su coherencia interna. Al no distinguir el concepto general de "igualdad" (como razonabilidad jurídica del trato diferente) del de prohibición de discriminación por determinados rasgos sospechosos (raza, sexo, etc.), ante los cuales no debería bastar el criterio de la razonabilidad, sino que el juicio debería tornarse más exigente (proporcionalidad, escrutinio estricto, etc.), o dicho con otras palabras, al no distinguir entre discriminación en sentido amplio y en sentido estricto, adoptando en principio un criterio judicial de examen muy deferente hacia la autoridad que establece la diferencia de trato, es lógico que el Tribunal tienda a "inhibir" su juicio a favor de dicha autoridad nacional y que no le asigne a la prohibición de discriminación más que un valor secundario o subsidiario, meramente relacional, respecto del resto de derechos del Convenio.

En otros lugares he intentado ordenar sistemáticamente los conceptos aludidos, así que no me detendré aquí más en ellos ${ }^{9}$. Tan sólo retendré la necesidad de distinguir entre igualdad en general y prohibición de discriminación por ciertos rasgos como la raza o la etnia, de afirmar el valor sustantivo o autónomo y no meramente relacional de la prohibición de discriminación en sentido estricto y, en coherencia con ello, de endurecer el examen judicial cuando una discriminación de este tipo sea invocada, adoptando un estándar más exigente que el de mera razonabilidad y parcialmente diferente según el rasgo sospechoso en presencia (sexo, raza, orientación sexual, etc.) y el concreto escenario social de conflicto planteado.

El propio Consejo de Europa ha intentando levantar el freno que supone el vigente art. 14 del Convenio y su interpretación por parte del Tribunal Europeo a través de la aprobación del Protocolo número $12^{10}$, que reconoce una prohibición de discriminación amplia y no como la vigente, circunscrita a los derechos expresamente reconocidos en el Convenio o sus protocolos. El artículo primero de este Protocolo reza: "El ejercicio de cualquier derecho reconocido por la ley será asegurado sin ninguna discriminación fundada, en particular, en razón de género, raza, color, lengua, religión, opiniones políticas o de cualquier otro tipo, origen nacional o social, pertenencia a una minoría nacional, riqueza, nacimiento o cualquier otra situación ${ }^{11 \text { ”. }}$

${ }^{9}$ Últimamente, entre otros: "El derecho fundamental a no ser discriminado por razón de sexo” en el libro La discriminación por razón de sexo tras 25 años de la Constitución española, Cuadernos de Derecho Judicial, Consejo General del Poder Judicial, Madrid, 2.004, pp. 23-108; “Homosexualidad y Constitución”, Revista Española de Derecho Constitucional, núm. 73, enero-abril 2.005, pp. 1-46; y "La prohibición de discriminación racial o étnica...”, ob.cit.

${ }^{10}$ Abierto a la firma el 4 de noviembre de 2.000 (en la significativa fecha del quincuagésimo aniversario del Convenio) y que ha entrado en vigor el 4 de octubre de 2.005 (en España el 1 de abril de 2.005).

${ }^{11}$ Como se ve, se mantiene la inercia en el sistema de protección del Consejo de Europa de ir en esta materia un par de pasos por detrás de lo que podríamos denominar "estándar actual de protección de los derechos”, 
En el Informe Aclaratorio oficial de este Protocolo, se pone de manifiesto la escasa operatividad actual del art. 14 del Convenio ${ }^{12}$, su incapacidad para distinguir los diversos tipos de discriminación y la escasamente significativa interpretación por parte del Tribunal Europeo de dicha disposición, sobre todo en materia de las discriminaciones raciales y sexuales. En efecto, es llamativa la esquizofrenia que resulta, por un lado, de la intensa actividad desplegada por el Consejo de Europa a favor de la igualdad entre mujeres y hombres y en contra del racismo y la xenofobia y, de otro lado, de la magra jurisprudencia del Tribunal Europeo precisamente en estas sensibles y críticas materias. A partir del Protocolo número 12, se ponen las bases, por fin, para un desarrollo serio y sin cortapisas de la prohibición de discriminación racial, sexual, etc. también en la jurisprudencia del Tribunal Europeo de Derechos Humanos. Pero en tanto lo nuevo no termina de nacer y lo viejo no acaba de morir, nos encontramos todavía con la estrecha jurisprudencia actual del Tribunal sobre el art. 14 del Convenio.

Otro punto verdaderamente sorprendente y criticable de esta jurisprudencia radica en que, así como el Tribunal ha venido protegiendo hasta cierto punto la discriminación por orientación sexual, o, sobre todo últimamente, por sexo, o por nacimiento, e incluso por nacionalidad ${ }^{13}$, la tutela frente a las discriminaciones raciales ha sido, sin embargo, escasa, con vacilaciones importantes y con Sentencias tan discutibles la del caso Ostrava. Esto es sorprendente porque, como afirma R. Dworkin, la discriminación racial es la más odiosa de todas porque "expresa desprecio y es profundamente injusta... es completamente destructora de las vidas de sus víctimas... no les priva simplemente de alguna oportunidad abierta a otros, sino que les daña en casi todos los proyectos y esperanzas que puedan concebir»14. La discriminación racial, por un lado, estigmatiza a sus víctimas ${ }^{15} \mathrm{y}$, por otro, las convierte en "minorías aisladas y sin voz ${ }^{16,}$,

ya que se opta por incluir la misma lista que hoy vige en el art. 14 del Convenio, sin añadir otros rasgos sospechosos como la orientación sexual (a pesar de que el Tribunal en este punto sí ha realizado una interpretación muy protectora de los derechos de homosexuales y transexuales -ver: "Homosexualidad...", ob.cit., pp. 119-128-), la edad o la discapacidad. Aunque la lista es abierta, obviamente, la presencia explícita en ella despliega efectos interpretativos directos de relevante significado.

12 Así como la singularidad de que no reconozca un principio general de igualdad (discriminación en sentido amplio), a diferencia del resto de textos internacionales comparables. Bien es cierto que el Tribunal lo halló implícito muy pronto, como "igualdad de trato", desde la seminal Sentencia del caso lingüístico belga de 23 de julio de 1.968 (y que, más aún, puede decirse que viene otorgando al art. 14 -en principio, una cláusula de discriminación en sentido estricto- no ese significado, sino el de mera cláusula general de igualdad o de discriminación en sentido amplio; se produce aquí una paradoja interesante).

${ }^{13}$ Ver. E. Roca, ob.cit., pp. 675-678.

${ }^{14}$ Sovereign Virtue. The Theory and Practice of Equality, Harvard Univ. Press, 2.000, p. 407.

${ }^{15}$ En el Derecho anti-discriminatorio, la teoría del estigma procede de Kenneth L. Karst ("Equal Citizenship under the Fourtheenth Amendment”, Harvard Law Review, vol. 91, nov. 1.977, pp. 1-68). Para este autor, el corazón de la idea de igualdad es el derecho de igual ciudadanía, que garantiza a cada individuo el derecho a ser tratado por la sociedad como un miembro respetado, responsable y participante. Enunciado de modo negativo, el derecho de igual ciudadanía prohíbe a la sociedad tratar a un individuo como un miembro de una casta inferior o dependiente o como un no-participante. En otras palabras, el derecho de igual ciudadanía protege contra la degradación o imposición de un estigma, que es la actitud con la que "los normales", "la mayoría” miran a aquellos que son diferentes. Citando a Goffman, Karst afirmará: "la persona víctima de un estigma no es del todo humano”. No todas las desigualdades estigmatizan. Los efectos del estigma recaen sobre las víctimas, dañando su autoestima, de modo que la mayoría llegan a 
De hecho, el origen del Derecho anti-discriminario en Estados Unidos se halla precisamente en la lucha contra la discriminación racial. Y existe una voluminosa y creciente normativa internacional protectora de las minorías étnicas y raciales ${ }^{17}$. Sin embargo, como se ha indicado, la jurisprudencia del Tribunal de Estrasburgo tiene más sombras que luces en este punto. Veámoslo.

II. LA JURISPRUDENCIA ANTERIOR A LA SENTENCIA D.H. Y OTROS CONTRA LA REPÚBLICA CHECHA, DE 7 DE FEBRERO DE 2.006

a) Introducción: los escenarios de conflicto.

Antes de D.H. y otros contra la República Checa, se pueden distinguir seis escenarios de conflicto: agresiones racistas por agentes de la autoridad; agresiones racistas vecinales y deficiente tutela judicial posterior; expulsión de caravanas; discriminación en frontera; discriminación racial e imparcialidad judicial en juicio por jurados; y discurso racista y libertad de información.

\section{b) Agresiones racistas por agentes de la autoridad.}

Por desgracia, éste sigue siendo todavía el principal escenario de conflicto derivado de la discriminación racial. Tanto por número de Sentencias, como, peor aún, por la gravedad de los ataques dirigido contra los miembros de las minorías étnicas, casi siempre gitanos. En un asunto, Bekos y Koutropoulos contra Grecia, de 13 de diciembre de 2.005, se trata tan "sólo" de actos de brutalidad policial durante la detención por móviles racistas (afectando por tanto, al derecho a no sufrir torturas ni penas o tratos inhumanos o degradantes del art. 3 del Convenio), pero en todos los demás los gitanos fueron asesinados por los agentes de la autoridad de países del Este (resultando una lesión, por consiguiente, no sólo de la protección jurídica de la vida del art. 2 del Convenio ${ }^{18}$, sino también de este derecho en combinación con la

aceptar como "naturales” las desigualdades perjudiciales que reciben, pero también recaen sobre toda la sociedad, que llega a elaborar una ideología del estigma para justificarlo. Me parece fuera de toda duda que las minorías raciales (no así las mujeres, por ejemplo) encajan a la perfección en la categoría de "casta” víctima de un "estigma”. Esto determina, en mi opinión, que las normas contra la discriminación racial puedan ser (y deban ser) más incisivas que en otro tipo de discriminaciones - concediendo, por ejemplo, un preferencia a las acciones positivas dirigidas a este colectivo y un mayor espacio a las discriminaciones positivas.

${ }^{16}$ Las minorías raciales son, en sentido estricto, "minorías aisladas y sin voz" en el proceso político. Como se sabe, la doctrina de las "discrete and insular minorities" fue acuñada por el Tribunal Supremo norteamericano en la cuarta nota de pie de página de la Sentencia Carolene Products v. U.S., de 1.938 (ponente: Stone) y ha sido formulada teóricamente por John H. Ely ("Equal Citizenship under the XIV Amendment”, Harvard Law Review, vol. 91, nov. 1.977, pp. 69 ss.). Según esta teoría, la prohibición constitucional de discriminación concierne principalmente a la protección judicial de aquellos grupos minoritarios que son incapaces de defenderse en la arena política a causa de su privación de derechos o por sufrir estereotipos negativos. También desde este punto de vista se refuerza la idea de que el derecho contra la discriminación racial ha de ser particularmente intenso e incisivo.

${ }^{17}$ En forma de declaraciones generales sobre derechos humanos (art. 2.1 de la Declaración Universal de Derechos Humanos, art. 2.1 del Pacto Internacional de Derechos Civiles y Políticos, además del art. 14 del Convenio de Roma), o de textos específicos (universales, como la Convención internacional sobre la eliminación de todas las formas de discriminación racial, aprobada por la Asamblea General de Naciones Unidas el 21 de diciembre de 1.965, o el Convenio n 111 OIT, o regionales, como el Convenio Marco núm. 157 del Consejo de Europa para la protección de las minorías nacionales, ratificado por España el 1 de febrero de 1.995).

${ }^{18}$ Para un análisis de esta disposición, permítaseme la remisión al trabajo: "La protección jurídica de la vida, un derecho en transformación y expansión. Artículo 2 CEDH y Protocolos 6 y 13”, en La Europa de 
prohibición de discriminación racial del art. 14). En esta serie de casos hay un “antes” y un "después” marcado por el memorable voto particular del magistrado Bonello en la Sentencia Anguelova contra Bulgaria de 13 de septiembre de 2.002 y la posterior Sentencia Nachova y otros contra Bulgaria, de 6 de julio de 2.005.

Antes del caso "Nachova”, en los asuntos Velikova contra Bulgaria, de 18 de mayo de 2.000 y Anguelova contra Bulgaria, de 13 de septiembre de 2.002, el Tribunal se enfrentó a las alegaciones de móviles racistas en las muertes de algunas personas gitanas en dependencias policiales, argumentando del mismo modo: exigiendo una prueba de tales actitudes “más allá de una duda razonable”. Un estándar de prueba tan astringente condujo, sin remisión, a que el Tribunal no apreciara discriminación racial (en conexión con la protección jurídica de la vida del art. 2 del Convenio -que sí se consideraba lesionado): "El material ante nosotros no permite al Tribunal apreciar, más allá de una duda razonable, que el asesinato... y la carencia de una investigación significativa fueran motivados por un prejuicio racial”. Y eso que el Tribunal, en ambos casos, observó que la alegación por los demandantes del asesinato por móviles racistas "se basaba en razones serias" y que el Estado demandado, Bulgaria, no había ofrecido una explicación plausible a la muerte de las víctimas y a la omisión en la investigación posterior de ciertos aspectos que podrían haber iluminado los hechos.

A la Sentencia Anguelova le acompaña, como ya dije, un voto discrepante del magistrado Bonello de gran estatura técnica. Comienza observado que es "inquietante" que el Tribunal Europeo en sus más de cincuenta años de existencia no haya encontrado un solo caso de violación de la protección jurídica de la vida (art. 2) o frente a la tortura o los tratos inhumanos y degradantes (art. 3) inducidos por móviles racistas. "Leyendo los anales de la jurisprudencia, un observador no informado creerá que Europa carece de cualquier sospecha de racismo, intolerancia o xenofobia”. La Europa proyectada por esa jurisprudencia "es un cielo de fraternidad étnica”, en el cual "las gentes de los más diversos orígenes conviven sin preocupación, prejuicio o discriminación”. Constata también Bonello que de modo regular el Tribunal conoce casos en los que los miembros de una minoría vulnerable son privados de su vida o sufren malos tratos, pero ni una sola vez ha encontrado relación con su etnicidad: "kurdos, musulmanes y gitanos son una y otra vez asesinados, torturados o maltratados, pero el Tribunal no está convencido de que su raza, color, nacionalidad o lugar de origen tengan algo que ver con ello”. Con ironía, remata su idea: “el infortunio visita puntualmente a los grupos minoritarios en desventaja, pero sólo como resultado de una feliz coincidencia”. La luz roja se enciende ahora, de modo particular, con las sistemáticas violaciones de los artículos segundo y tercero del Convenio de los gitanos en Bulgaria (y no sólo por los casos que finalmente llegan ante el Tribunal, también trae a colación Bonello informes de Amnistía Internacional, de Naciones Unidas y del propio Consejo de Europa sobre el particular).

Bonello sitúa la raíz de este "escape de la realidad” en la regla probatoria de la “duda más allá de lo razonable”. A su juicio, el Tribunal, que, como regla general,

los Derechos. El Convenio Europeo de Derechos Humanos (J. García Roca y P. Santolaya coords.), CEPC, Madrid, 2.005, pp. 67-95. 
debe hacer los derechos "practicables y efectivos y no teóricos o ilusorios" (Artico contra Italia, de 13 de mayo de 1.980), no puede utilizar un estándar probatorio equivalente al que en un Estado se requiere para obtener una condena penal. Esta equivalencia convierte en "ilusoria, ineficaz e inalcanzable" a la protección contra la discriminación ${ }^{19}$ El magistrado discrepante invita, por ello, al Tribunal a "replantear" de modo "radical y creativo" su aproximación a la materia y le propone diversas vías: la técnica de la inversión de la carga de la prueba ${ }^{20}$, o la estimación de la violación del derecho si el Gobierno de que se trate no proporciona la información a la que sólo él tenía acceso $^{21}$, o la presunción de que cuando un miembro de un grupo desventajado sufre daño en un asunto donde las tensiones raciales son altas y la impunidad de los ofensores estatales epidémica, la carga de la prueba de que el suceso no fue étnicamente provocado debería corresponder al Estado. Y, por supuesto, habría también violación del art. 14 (en relación con el art. 2 o el 3) cuando el Estado no investigue adecuadamente los móviles racistas del ataque a la vida o la integridad física y moral del miembro de una minoría étnica (de modo semejante a como sucede en relación con los derechos del art. 2 y 3 del Convenio). Es decir, Bonillo propone la acuñación judicial de una dimensión procedimental de protección de la prohibición de discriminación, semejante a la que el Tribunal ha creado en relación con los derechos a la vida y a la integridad física y moral.

Lo cierto es que el Tribunal Europeo ha hecho suyas las propuestas del magistrado Bonello a partir de la capital Sentencia Nachova y otros contra Bulgaria, de 6 de julio de 2.005, en la que afirma que en los casos de privación de la vida en que se alegue prejuicio racista las autoridades estatales han de llevar a cabo "una investigación efectiva" sobre esta conexión; y, más concretamente, tienen "el deber adicional de adoptar las medidas razonables para desenmascarar cualquier motivación racista en un incidente que implique el uso de la fuerza por los agentes estatales”. En estos casos, "la carga de probar que no ha habido discriminación corresponde a las autoridades nacionales demandadas"; particularmente en casos de violencia racista, "el gobierno debe probar la ausencia de una actitud subjetiva concreta por parte de las personas afectadas ${ }^{22 \text { ". }}$ Añade que la "violencia racial es una ofensa particular a la dignidad humana que, a la vista de sus peligrosas consecuencias, requiere por parte de las autoridades de

\footnotetext{
${ }^{19}$ Bonello sostiene que tanto la Corte Interamericana de Derechos Humanos como el Tribunal Supremo Federal de los Estados Unidos han establecido estándares mucho más razonables. La primera ha afirmado (en Velásquez Rodríguez contra Honduras, de 29 de julio de 1.988) que "la protección internacional de los derechos humanos no debe confundirse con la justicia penal” y el Tribunal norteamericano, como es conocido, una vez que admite la prima facie discriminatoria ofrecida por el demandante (los indicios suficientes de discriminación de nuestro Tribunal Constitucional), invierte la carga de la prueba, de modo que corresponde al demandado demostrar que su práctica no es discriminatoria.

20 "Una técnica que el Tribunal ha adoptado con éxito cuando la alternativa habría hecho la búsqueda de la verdad imposible”, como por ejemplo en los casos de desaparición de detenidos una vez conducidos a dependencias policiales, en los que corresponde al Estado ofrecer una explicación satisfactoria.

${ }^{21}$ De modo semejante a la protección "procedimental" que el Tribunal ha creado en relación con la protección jurídica de la vida o frente a las torturas y tratos inhumanos (ver: "La protección jurídica de la vida...”, ob.cit., p. 78 ss. y el comentario a la Sentencia McCann y otros contra Reino Unido, de 27 de septiembre de 1.995).

${ }_{22}$ El Tribunal concluyó que se había lesionado el art. 14 en relación con el art. 2 porque las autoridades estatales no investigaron si los hechos podrían haber sido racialmente motivados.
} 
una vigilancia especial y una reacción vigorosa”. En consecuencia, "las autoridades estatales deben usar todos los medios a su alcance para combatir el racismo y la violencia racista, reforzando una comprensión de la democracia como una sociedad en la que la diversidad no es percibida como una amenaza, sino como una fuente de riqueza”. Nachova es una Sentencia en la que, por fin, el Tribunal se toma en serio la prohibición de discriminación del art. 14 del Convenio de Roma respecto de la violencia racial.

A esta Sentencia la acompaña, empero, el voto particular del magistrado Bratza, que no está de acuerdo completamente con la nueva doctrina y además cree que en el caso concreto no se ha justificado la animosidad racista de las muertes de las dos personas gitanas (y, por tanto, el Tribunal no debería haber hallado la violación del art. 14 en combinación con el art. 2). Y también el del voto discrepante de nada menos que siete magistrados, aunque su divergencia con la mayoría no es porque no creyeran que se había producido esa lesión del art. 14 en relación con el art. 2, sino porque consideraban que la carencia de la investigación estatal era sólo uno más de entre los indicios de violencia racial ${ }^{23}$, de modo que la distinción de la dimensión procedimental empleada por la mayoría del Tribunal resultaría inadecuada.

La doctrina Nachova es reiterada por el Tribunal en todos los casos semejantes posteriores: Bekos y Koutropoulos contra Grecia, de 13 de diciembre de $2.005^{24}$ y Ognyanova y Chocan contra Bulgaria, de 23 de febrero de $2.006^{25}$. Y también en Timishev contra Rusia, de 13 de diciembre de 2.005, aunque el caso no es semejante, como veremos.

\section{c) Agresiones racistas vecinales y deficiente tutela judicial posterior.}

Sólo existe un asunto, el de Moldovan y otros contra Rumanía, de 12 de julio de 2.005, creo que razonablemente resuelto. Tras un altercado en el que resultó muerta una persona, los vecinos emprenden una "represalia" contra la comunidad gitana del pueblo, con diversos actos violentos, quema de viviendas, etc. El Tribunal constata que estos ataques fueron provocados por ser gitanas sus víctimas, así como que las autoridades administrativas y judiciales habían dilatado al máximo la reparación posterior de los daños derivados de la destrucción de las viviendas. "La etnicidad gitana de los demandantes parece haber sido decisiva para el resultado de los procedimientos domésticos" y dado que el Gobierno rumano no ofrece una justificación plausible para esta diferencia perjudicial de trato, el Tribunal Europeo concluye que habría habido violación del art. 14 en relación con los derechos del art. 6 (proceso equitativo) y 8 (respeto a la vida privada y familiar).

\footnotetext{
${ }^{23}$ También estarían los hechos de que los disparos se efectuaron en el barrio gitano de la ciudad, que la policía conocía que las víctimas eran gitanos, que la existencia de prejuicios en Bulgaria contra los gitanos está bien acreditada, que el agente que disparó dijo después de hacerlo: “malditos gitanos”, etc.

${ }^{24}$ Las autoridades no habrían adoptado todos los pasos para investigar si en el origen de los hechos (actos de brutalidad policial durante la detención de dos gitanos griegos) hubo prejuicio racial, por lo que habría habido violación del art. 3 (prohibición de malos tratos) en combinación con el art. 14.

${ }^{25}$ La víctima, un gitano, había muerto al caer desde una ventana de una comisaría búlgara. El Tribunal aprecia una violación del art. 2 del Convenio, pero no del art. 14 en este caso, puesto que, aunque cita la doctrina Nachova, a diferencia de los otros casos, no figura en el asunto ninguna concreta indicación de que las actitudes racistas jugaran algún papel en los hechos, ni los demandantes aportaron un solo dato en este sentido.
} 


\section{d) Expulsión de caravanas.}

Las cinco Sentencias del Tribunal Europeo de Derechos Humanos del año 2.001 sobre expulsiones, por razones urbanísticas, de los terrenos ipropios! ocupados por caravanas de gitanos son también profundamente desalentadoras ${ }^{26}$. En el caso Coster, por ejemplo, el Tribunal consideró que la vida en caravana forma parte integrante de la identidad gitana, ya que se inscribe en su larga tradición de viajeros, incluso aunque se instalen durante largos periodos en un mismo lugar a fin de, por ejemplo, facilitar la educación de los hijos. Por ello el Tribunal constata que las decisiones de los servicios de ordenación del territorio negando al demandante la autorización de permanecer en el terreno de su propiedad con una caravana, es una injerencia en el derecho al respeto de su vida privada y familiar (art. 8 CEDH). La cuestión siguiente es determinar si está justificada o no, es decir, si está prevista por la ley (lo que sucede), si persigue uno o varios fines legítimos (en el caso también concurre en forma de protección del medio ambiente) y si es necesaria en una sociedad democrática para alcanzar tales fines. El Tribunal reconoce en este punto un cierto margen de apreciación a las autoridades nacionales, que se encuentran en principio mejor situadas que él para pronunciarse sobre la situación y las necesidades locales. Y por ello, el Tribunal admite que "no está en disposición de contestar el dictamen emitido por las autoridades nacionales en este asunto, según el cual el uso particular de un terreno suscita objeciones legítimas en materia de ordenación”. El Tribunal "no puede ir a todos los lugares para apreciar el impacto de cierto proyecto en una región dada en cuanto a la belleza del lugar, etc." En consecuencia, "en materia de políticas de ordenación territoriales, las autoridades nacionales gozan en principio de un margen de apreciación extenso". Y aunque el Tribunal observa que "está creciendo un consenso internacional en el seno de los Estados del Consejo de Europa para reconocer las necesidades particulares de las minorías y la obligación de proteger su seguridad, identidad y modo de vida...", se confiesa "no convencido de que dicho consenso sea suficientemente concreto como para que se puedan obtener directrices en cuando al comportamiento o a las normas que los Estados consideren como deseables en una situación dada...” Y concreta esta afirmación respecto de la minoría gitana: "la vulnerabilidad de los gitanos... implica conceder una atención especial a sus necesidades y a su modo de vida propio". El art. 8 del Convenio de Roma "impone, por lo tanto, a los Estados la obligación positiva de permitir a los gitanos continuar con su modo de vida". En principio, "los gitanos son libres de instalarse en cualquier emplazamiento para caravanas que tengan licencia" y "a no ser tratados peor que cualquier no gitano que desee vivir en una caravana". Sin embargo, "se desprende que no se ha llegado a suministrar un número adecuado de emplazamientos que los gitanos encuentren aceptables y en los que puedan instalar legalmente sus caravanas a un precio a su alcance". Pero de aquí no se deriva la obligación para el Reino Unido de "poner a disposición de la comunidad gitana un número adecuado de emplazamientos debidamente equipados”. Por ello, el Reino Unido no habría violado el art. 8 del Convenio.

${ }^{26}$ Sentencias Beard, Coster, Chapman, Jane Smith y Lee contra el Reino Unido, todas ellas de 18 de enero de 2.001 . 
La Sentencia es acompañada por un Voto Particular suscrito por siete Jueces, entre ellos el de J.A. Pastor Ridruejo, que sí consideran que se ha violado el derecho a la vida privada y familiar del recurrente, pues "no se han indicado otros lugares en la región que ofrezcan emplazamientos libres en los que los demandantes hubieran podido instalarse"; por este motivo, la medida de expulsión es desproporcionada. Me resulta más consistente este voto discrepante que la opinión mayoritaria. El Tribunal no cree que lesione el derecho al respeto de la vida privada y familiar la prohibición administrativa de instalarse con una caravana en una parcela de titularidad propia en atención a que se estropea el paisaje. La alternativa propuesta por el Estado era el hacinamiento de caravanas en lugares especiales, lo cual, sea dicho de paso, recuerda a otras épocas ominosas (en mi opinión, la política segregacionista es en sí misma sospechosa de discriminación -lo veremos también en relación con D.H. y otros contra República Checa), pero ni siquiera está disponible para todos los que la desean. De modo que el Tribunal reconoce que el asentamiento de gitanos en caravanas está protegido por el art. 8 del Convenio de Roma, pero ni invalida que se impida al recurrente hacerlo en su propiedad (porque el Estado tiene un amplio margen de apreciación) ni halla ilegítimo que tampoco pueda instalarse en algún lugar habilitado para ello (porque eso sería tanto como convertir los derechos del art. 8 en derechos de prestación). Resultado: el recurrente tiene un derecho con un simple recubrimiento formal pero sin contenido, ya que no puede de ningún modo ejercerlo. Un inexistente pero efectivo derecho al paisaje lo ha derrotado.

\section{e) Discriminación en frontera.}

En el asunto Timishev contra Rusia, de 13 de diciembre de 2.005, el Tribunal examina la negativa a admitir "chechenios" en una frontera rusa. Naturalmente, concluirá que se trata de una desigualdad de trato en el ejercicio de la libertad de circulación basada en el origen étnico y, por tanto, violatoria del art. 14 del Convenio (en relación con el art. 2 del Protocolo número 4). Pero esta Sentencia, más allá del fallo, tiene cierto interés doctrinal. Como, por ejemplo, la distinción que traza entre "raza” y "etnia”: ambos conceptos "están conectados y se solapan”. Mientras que "la noción de "raza” tiene como fundamento la idea de una clasificación biológica de los seres humanos en sub-especies de acuerdo a rasgos morfológicos como el color de la piel o las características faciales", la "etnicidad tiene su origen en la idea de grupos sociales marcados por una común nacionalidad, afiliación tribal, fe religiosa, lengua compartida, orígenes culturales o tradicionales"27.

Esta Sentencia reitera la doctrina Nachova, pero añade una afirmación de interés: "Ninguna diferencia de trato que se base exclusivamente o de modo decisivo en el origen étnico de una persona es capaz de constituir una justificación objetiva en una sociedad democrática contemporánea construida sobre los principios de pluralismo y respeto por las diferenciales culturales”. Esta tesis está guiada por una buena intención, y tiene sentido en relación con la prohibición de las discriminaciones directas e

\footnotetext{
${ }^{27}$ Para una discusión crítica de las relaciones entre los conceptos de "raza” y “etnia”, ver mi trabajo “La prohibición de discriminación racial...”, ob.cit., pp. 91 ss. Entiendo que guardan entre sí una relación de género (etnia) a especie (raza).
} 
indirectas (esto es, de todo trato que perjudique a los miembros de un grupo étnico únicamente por su pertenencia al mismo), pero es poco reflexiva porque, tomada al pie de la letra, impediría por completo las diferencias jurídicas de trato que, como las acciones y/o las discriminaciones positivas, pretendieran igualar las oportunidades de las minorías étnicas respecto del grupo social mayoritario. Un trato jurídico idéntico consolidaría la diferente situación fáctica de unos grupos y otros dentro de una sociedad. La afirmación sólo tiene sentido respecto de los tratos jurídicos desfavorables para la minoría racial, no para los favorables.

f) Discriminación racial e imparcialidad judicial en juicio por jurados.

Son de interés tres Sentencias. La primera en el tiempo es Remli c. Francia, de 30 de marzo de 1.996. Un acusado de origen norteafricano alegó que había oído a un miembro de su jurado decir "soy racista”. Sin embargo, el tribunal se negó a considerar siquiera la recusación del jurado con la única afirmación de que no podía tomar conocimiento de hechos ocurridos fuera de su presencia. El Tribunal Europeo, tras indicar que "el art. 6.1 impone la obligación a cada tribunal nacional de controlar que, una vez constituido, sigue siendo imparcial”, estimó que el tribunal francés no lo hizo, al no permitir la posibilidad de impugnar al jurado racista, $\mathrm{y}$, por consiguiente, produjo una violación de tal precepto. Una situación semejante en un juicio por jurados, pero no idéntica, se produjo en Gregory c. Reino Unido, de 25 de febrero de 1.997. El Tribunal de Estrasburgo observó que, a diferencia de lo sucedido en Remli, donde el juez no adoptó reacción alguna frente a la alegación de la declaración racista de un jurado anónimo (que notificó al juez que algunos compañeros jurados habían mostrado, en las deliberaciones internas, actitudes racistas -el acusado era de raza negra-), el juez británico sí hizo frente, por varias vías ${ }^{28}$, a una alegación de racismo de un jurado que, aunque vaga e imprecisa, parecía no carecer de fundamento (y, por tanto, no hubo lesión del art. 6.1). Por último, Sander c. Reino Unido, de 9 de mayo de 2.000, planteó un supuesto casi idéntico al de Gregory, aunque con algunas divergencias significativas. En ese asunto un miembro del jurado comunicó al juez que otros dos jurados habían proferido chistes y expresiones racistas contra el acusado, de origen asiático. Si bien poco después todos los miembros del jurado manifestaron por escrito que tal crítica era infundada, uno de ellos confesó haber contado chistes racistas sobre el acusado. El Tribunal Europeo afirmó que tales bromas no podían considerarse a la ligera, y mucho menos en el contexto de un proceso penal (otra cosa sería en una "atmósfera informal o íntima”). Dada "la importancia que los Estados miembros otorgan a la necesidad de combatir el racismo”, el Tribunal consideró que el juez "debía haber reaccionado de modo más contundente” (pues no se llegó a descartar a ningún jurado). Al no hacerlo, violó los requerimientos de imparcialidad judicial del art. 6 del Convenio.

Así pues, en este punto sí se observa un Tribunal Europeo exigente que utiliza el microscopio judicial para evitar que los prejuicios raciales contaminen de modo

\footnotetext{
${ }^{28}$ Sobre todo, hablando con los abogados de defensa y acusación y recordando enérgicamente al jurado (sin mencionar expresamente las palabras "prejuicio racial”) que debían alejar de sus mentes "cualquier clase de prejuicio".
} 
alguno la imparcialidad del órgano juzgador. La seriedad con que el Tribunal aborda la interpretación del art. 6 del Convenio (la independencia e imparcialidad judicial) atrae esta exégesis rigurosa, que contrasta con la débil protección general contra la discriminación racial que lleva a cabo en otros escenarios de conflicto.

\section{g) Discurso racista y libertad de información.}

En la controvertida Sentencia Jersild contra Dinamarca, de 23 de septiembre de 1.994, el Tribunal Europeo consideró contraria a la libertad de informar del art. 10 del Convenio de Roma la sanción penal que las autoridades danesas habían infligido a un periodista de televisión por un reportaje en el que entrevistaba a portavoces de un grupo racista danés, los Greenjackets, en el que éstos vertían afirmaciones como que "los negros no son seres humanos, sino animales" y "se parecen a gorilas". La Sentencia, a pesar de que enfatiza "la vital importancia de combatir el discurso racista en todas sus formas y manifestaciones”, entiende, sin embargo, que la libertad de informar juega un papel esencial en el sistema democrático, que el periodista no tenía una intención racista y que se había limitado a transmitir tales intolerables contenidos desde una posición neutral o no incentivadora de las declaraciones (acogiendo así el Tribunal la doctrina del reportaje neutral), por lo que finalmente ampara al profesional de la información. Bien es verdad que hasta seis magistrados presentaron dos votos discrepantes alegando que "la protección de las minorías raciales no puede tener menor peso que el derecho a informar". El asunto dista de estar claro, pero, en el contexto de la jurisprudencia del Tribunal, no resulta raro que en el balance de intereses pierda, de nuevo, la discriminación racial.

En conclusión, por tanto, hay que reconocer que algunos escenarios de conflicto están mejor resueltos que otros, aunque la jurisprudencia del Tribunal Europeo en materia de discriminación racial se ha ido expandiendo y ganando en intensidad (sobre todo a partir de la reciente Sentencia Nachova, de 2.005). El asunto D.H. y otros contra la República Checa ha venido, sin embargo, a romper esa tendencia de mayor protección hacia las minorías étnicas y raciales, llevando al Tribunal a regresar a la aproximación fría, formalista y race-.blind que el sostuvo habitualmente antes del asunto Nachova.

\section{ANÁLISIS DEL CASO OSTRAVA}

En el caso de D.H. y otros contra la República Checa, de 7 de febrero de 2.006, el Tribunal Europeo desestima una demanda contra ese Estado presentada por dieciocho nacionales pertenecientes a la comunidad gitana por discriminación racial o étnica en el ejercicio de su derecho de educación. Entre 1.996 y 1.999 los demandantes fueron ubicados en escuelas especiales en Ostrava, bien directamente o bien tras un primer periodo de formación en una escuela ordinaria de primaria. Las escuelas especiales son una categoría de escuelas especializadas dirigidas a niños con dificultades de aprendizaje incapaces de asistir a las escuelas ordinarias. La decisión de enviar a un niño a una escuela especial es tomada por el director de la escuela tras un examen que mide la capacidad intelectual del niño (formulado y evaluado por un Centro de psicología y orientación educativas), y requiere el consentimiento de los padres o representantes legales del menor. 
Los padres de los demandantes habían consentido enviar a sus hijos a las escuelas especiales, pero en un momento posterior solicitaron a la autoridad educativa de Ostrava que reconsiderara esta decisión porque desconfiaban del examen realizado para medir la capacidad intelectual de sus hijos y porque no habían sido suficientemente informados de las consecuencias de enviar a sus hijos a una escuela "especial”. La autoridad denegó la solicitud alegando que no cumplía con los requisitos formales legalmente previstos para apelar la decisión (se había presentado de modo extemporáneo).

Contra esta denegación plantearon una demanda constitucional invocando como argumento principal que habrían sufrido una discriminación de facto en el funcionamiento general del sistema educativo. Para superar el obstáculo formal que había permitido a la autoridad educativa rechazar su demanda, razonaban que su caso implicaba una violación continua de sus derechos y que afectaba a intereses generales, más allá de los personales. Sostenían, en efecto, que el sistema educativo había provocado de facto una segregación racial, manifestada en la existencia de dos sistemas educativos independientes para miembros de grupos raciales diferentes, escuelas especiales, sobre todo para los Roma o gitanos, y escuelas ordinarias para la mayoría de la población. Este trato diferenciado no tendría una justificación objetiva y razonable y privaría a los primeros de su derecho a la educación, ya que el currículo obtenido en las escuelas especiales era inferior al de las ordinarias y sus estudiantes eran incapaces de retornar al sistema principal de educación.

El Tribunal Constitucional checo desestimó la demanda por entender que no era su papel hacer valoraciones de tipo social y político sobre cuál es la mejor forma de organizar el sistema educativo y sus efectos sociales (y, por tanto, carecía de jurisdicción) y que los demandantes no habían aportado pruebas concretas en apoyo de sus alegaciones, además de que no habían ejercido en su momento su derecho de apelación contra la decisión de re-ubicar a sus hijos en las escuelas especiales (y, por tanto, la demanda era manifiestamente infundada).

\section{a) Los argumentos del Tribunal.}

Con estos antecedentes, el Tribunal Europeo de Derechos Humanos examina la posible violación de la prohibición de discriminación del art. 14 CEDH en relación con el derecho a la educación del art. 2 del Protocolo primero ${ }^{29}$.

Comienza recordando, en primer lugar, su jurisprudencia general sobre el art. 14: discriminación como diferencia de trato no razonable y margen amplio de apreciación estatal.

El Tribunal observa que la demanda se apoya en argumentos serios. También hace notar que diversas organizaciones, incluidas algunas del propio Consejo de Europa ${ }^{30}$, han manifestado su preocupación por que los niños gitanos checos sean confinados

\footnotetext{
29 “A ninguna persona se le denegará el derecho de educación. En el ejercicio de las funciones que asuma en relación con la educación y la enseñanza, el Estado deberá respetar el derecho de los padres a asegurar tal educación y enseñanza de conformidad con sus propias convicciones religiosas y filosóficas”.

${ }^{30}$ Así, por ejemplo, la Comisión Europea contra el Racismo y la Intolerancia (ECRI). En su opinión discrepante, el Juez Cabral Barreto llamará a estrados a uno de sus Informes sobre la República Checa (el tercero, de 2.004).
} 
en escuelas especiales y por su dificultad en acceder a las escuelas ordinarias. Pero el Tribunal, haciendo suyo el argumento del Tribunal Constitucional checo, afirma que no es su papel evaluar el contexto social en su conjunto, sino que debe limitarse a examinar las demandas individuales presentadas ante él en el caso concreto para determinar si la ubicación de los demandantes en escuelas especiales se debió a razones de origen étnico o racial. Y recuerda que si una determinada política despliega efectos perjudiciales sobre un grupo concreto, puede ser considerada discriminatoria aunque no se dirija específicamente a ese grupo; sin embargo, "las estadísticas no son por sí mismas suficientes para revelar una práctica como discriminatoria” (Jordan c. Reino Unido, de 4 de septiembre de 2.001). Este argumento es central para la resolución del caso. Volveremos sobre él más adelante.

También sostiene, antes de entrar en el fondo del asunto (aunque, claramente, de un modo que le va preparando el sentido desestimatorio del fallo), que la fijación del sistema y del currículo escolar es competencia, en principio, de los Estados miembros. Esta organización puede legítimamente variar en el tiempo y según el país (Valsamis v. Grecia, 18 de diciembre de $1.996^{31}$ ). Respecto de alumnos con necesidades especiales, el Tribunal acepta que la elección entre específicos tipos de escuela para cada uno con centros altamente especializados o centros unificados con secciones especiales no es fácil ni puede hallarse una solución ideal. Implica un difícil ejercicio de valoración de los intereses contrapuestos en presencia. El Tribunal invoca aquí de nuevo la doctrina del margen de apreciación estatal para remitir a los Estados tal valoración.

Situada la litis desde este marco, muy contemporizador en línea de principio con las políticas educativas estatales (tanto que no haría falta seguir leyendo el resto de la Sentencia para adivinar cuál será el fallo), el Tribunal entra a examinar el asunto en concreto, formulando los siguientes argumentos:

$1^{\circ}$ ) El Gobierno checo ha demostrado que el sistema de escuelas especiales en el país no fue introducido sólo para atender a los niños gitanos y también que hace considerables esfuerzos para ayudar a ciertas categorías de alumnos a conseguir una educación básica. El Tribunal da por buena la tesis gubernamental de que el criterio para seleccionar a los demandantes no fue su raza ni origen étnico, sino sus dificultades para el aprendizaje, puestas de manifiesto por tests psicológicos.

$2^{\circ}$ ) La Sentencia insiste en este último aspecto, que podríamos denominar “técnico" de la cuestión. Si el propósito legítimo de las autoridades checas es adaptar el sistema educativo a las necesidades, aptitudes y dificultades de los niños, es lógico que sean los expertos en psicología educativa los únicos que puedan identificarlas. El Tribunal hace notar que nadie en el curso del proceso había cuestionado que los

\footnotetext{
${ }^{31}$ En este asunto, un niño griego de 12 años, testigo de Jehová, no acude a la parada celebrada con ocasión de la celebración de Día Nacional alegando razones de corte pacifista derivadas de su convicción religiosa, por lo que es sancionado con un día de suspensión escolar. El Tribunal no cree que esto lesione ni su derecho a la educación ni su libertad religiosa porque el significado de esa celebración no es militar, sino de exaltación de la libertad, la democracia, etc. Ahora bien, la Sentencia afirma que, aunque "no es tarea del Tribunal examinar las decisiones del Estado griego sobre el currículo educativo”, resulta sorprendente que se castigue a los alumnos con un día de suspensión escolar por no asistir a una parada que se realiza fuera del recinto escolar y en día de fiesta. Este caso no es, evidentemente, comparable al del asunto Ostrava.
} 
tests en el caso concreto hubieran sido administrados por profesionales cualificados (aunque los demandantes habían alegado que no existen reglas uniformes sobre la elección de tales pruebas o sobre la interpretación de los resultados). No se había demostrado tampoco que los psicólogos hubieran adoptado una actitud subjetiva determinada (prejuicio, hostilidad, etc.).

$3^{\circ}$ ) El Tribunal se cuida de no olvidar que los padres no habían presentado en su momento reclamación alguna contra la decisión de enviar a sus hijos a las escuelas especiales, a pesar de haber recibido una “clara información escrita” informándoles de ese hecho y de las posibilidades de impugnación. Más aún, todos dieron su consentimiento e incluso algunos padres pidieron expresamente que enviaran a sus hijos a una escuela especial. La Sentencia opone un estándar de diligencia parental (una suerte de diligencia de buen padre de familia, sin llamarla así) a la alegación de los padres de que su consentimiento no había sido, en realidad, (bien) informado: "era responsabilidad de los padres, como parte de su deber natural de asegurar que sus hijos reciban una educación, averiguar las oportunidades educativas ofrecidas por el Estado, cerciorarse de que ellos prestaban su consentimiento al envío de sus hijos a una escuela especial y, si fuera necesario, plantear una oportuna reclamación”.

$4^{\circ}$ ) A partir del hecho de que cuatro de los demandantes lograron entrar más tarde en la escuela ordinaria, el Tribunal encuentra pruebas de que, a diferencia de lo que sostenían los demandantes, la transferencia a las escuelas especiales no es un hecho irreversible.

En conclusión, y a pesar de tener en cuenta que los datos estadísticos "son preocupantes” y que la situación general de la educación de los niños gitanos en la República Checa "no es perfecta", el Tribunal encuentra que las medidas adoptadas en este caso contra los demandantes no son discriminatorias, esto es, que el envío de los niños a las escuelas especiales haya sido el resultado de un prejuicio racial. Y, por tanto, no habría habido violación del art. 14 CEDH en relación con el art. 2 CEDH.

b) Voto concurrente del Juez Costa.

El Juez Costa está de acuerdo con la mayoría, pero, confiesa, que sólo después de algunas "vacilaciones” y reconociendo que algunos argumentos del voto discrepante del Juez Cabral Barreto son "muy fuertes”.

Hablando en general, observa el Juez Costa que la situación de los gitanos en los Estados del Centro de Europa, donde son más numerosos que en otros lugares, “indudablemente plantea problemas". A pesar de los esfuerzos de los Gobiernos (fuertemente impulsados por el Consejo de Europa y por la Unión Europea) para mejorar su situación, los progresos son "lentos y difíciles". El Tribunal tuvo ocasión de comprobar, por ejemplo, que la comunidad gitana está expuesta a violación y discriminación en Eslovaquia (Çonka v. Bélgica, de 5 de mayo de $2.002^{32}$ ). Más recientemente, en el caso Nachova y otros v. Bulgaria, el Tribunal encontró que había razones para sospechar que ciertas actitudes racistas estaban en el

${ }^{32}$ Una familia de gitanos eslovacos, repetidamente asaltada por skinheads en su país ante la pasividad policial, decide huir a Bélgica, donde piden asilo político, que no se les concede; fueron arrestados y deportados y en el asunto debaten la regularidad de sus garantías como detenidos. 
origen de la violencia que había causado dos víctimas mortales gitanas. Por ello, encontró que se había violado el art. $14 \mathrm{CEDH}$, en relación con el art. 2 CEDH (derecho a la protección jurídica de la vida) porque las autoridades no habían adoptado todas las medidas posibles para averiguar si la conducta discriminatoria podría haber jugado un papel en los hechos. En consecuencia, concluye Costa, el Tribunal "debe ser extremadamente vigilante". Es además "bastante claro" que la situación general de la educación de los niños gitanos en la República Checa no es ni mucho menos perfecta.

Sin embargo, afirma Costa, los casos deben ser siempre examinados desde la perspectiva de las demandas individuales; en éste, el problema es: ¿fueron los demandantes desplazados a las escuelas especiales a causa de alguna actitud racista? Aquí, obviamente, "la duda se plantea y yace la dificultad”. El peligro es que, con la cobertura de las pruebas psicológicas, un grupo de la población escolar sea condenada a escuelas de menor nivel, con escasas oportunidades de mezclarse con compañeros de otros grupos étnicos y sin esperanza alguna de alcanzar una educación que les permita progresar. En el pasado se utilizaron test en algunos países para excluir a ciertos grupos sociales del ejercicio del derecho de sufragio. Ésta situación podría plantearse ahora con el ejercicio del derecho de educación.

Pero el Juez Costa reitera las razones que concurren en el caso y que impiden estimar la discriminación racial: no se ha cuestionado que los tests fueran realizados de modo profesional y objetivo, los padres consintieron en el reclutamiento de sus hijos en las escuelas especiales, éstas no se ocupan en la República Checa sólo de los niños gitanos, etc. Las pruebas tienden a apoyar los argumentos del Estado demandado. El problema en general, señala Costa, está en la propia existencia de escuelas especiales en varios países ${ }^{33}$. El debate es altamente complejo y, por ello, ¿debe ser juzgada la política educativa de la República Checa tan severamente?, ¿tanto como para estimar una discriminación racial en este caso? Costa contesta que el Tribunal hubiera ido muy lejos si hubiera hecho eso; habría distorsionado los hechos, las pruebas y se hubiera apartado radicalmente de su jurisprudencia, convirtiendo en obligación de los Estados una "discriminación positiva” de incremento de fondos para evitar que las escuelas especiales sufrieran el riesgo de convertirse en "ghettos" educativos.

\section{c) Opinión discrepante del Juez Cabral Barreto.}

A su juicio, se habría violado en este caso el art. 14 en relación con el art. 2 del Convenio. En primer lugar, realiza dos observaciones previas: $\left(1^{\mathrm{a}}\right)$ Cabral dice conocer los esfuerzos de la República Checa por integrar en su seno a la comunidad gitana ${ }^{34}$. $\left(2^{a}\right)$ Asimismo, se declara incapaz de llevar a cabo cualquier juicio de valor sobre las condiciones de vida de los gitanos en la República Checa o de si son mejores o

\footnotetext{
${ }^{33}$ Incluso en Francia, ejemplifica este Magistrado, el sistema de ecuación secundaria (collége) tiene muchos defensores, pero también grandes detractores. El establecimiento en 1.982 de "áreas de educación prioritaria” ha tenido éxito en corregir ciertas desigualdades, pero en las áreas donde éstas son mayores muchos jóvenes de extracción inmigrante ni siquiera llega a tener el francés como lengua nativa. El debate es “altamente complejo".

${ }^{34}$ De hecho, Cabral hace notar que el sistema educativo checo se halla en un proceso de transición, aboliendo este sistema de "escuelas especiales".
} 
peores que en otros Estados. Coincidiendo con una repetida afirmación de la mayoría (intentando desactivarla), observará que el papel del Tribunal sería tan sólo el de examinar si ha habido violación o no del Convenio en el caso concreto.

A continuación expone sus argumentos:

$1^{\circ}$ ) Un Informe del Estado checo de abril de 1.999 (en el marco de la Convención para la Protección de Minorías Nacionales) afirma que "Niños gitanos con capacidad intelectual media e incluso superior son a menudo ubicados en escuelas (especiales) sobre la base de resultados de pruebas psicológicas. Estas pruebas fueron concebidas para la mayoría de la población y no tomaron en específica consideración a los gitanos”. En esa época, en algunas “escuelas especializadas”, había entre un 80 y un $90 \%$ de alumnos gitanos. Según Cabral, "esto constituye un expreso reconocimiento por parte del Estado checo de las prácticas discriminatorias sufridas por los demandantes". Entre 1.996 y 1.999 éstos no fueron enviados a escuelas para discapacitados mentales a causa de su incapacidad mental; al contrario, ellos poseían una capacidad intelectual media o superior.

$2^{\circ}$ ) El tercer Informe sobre la República Checa de la Comisión Europea contra el racismo y la intolerancia (ECRI), hecho público el 8 de junio de 2.004, afirmaba, respecto del consentimiento de los padres a la hora de enviar a sus hijos a las escuelas especiales, que "los padres continúan careciendo de información respecto de las consecuencias negativas de largo alcance” derivadas de este hecho. En la práctica, subraya el Juez Cabral, los alumnos educados en una "escuela especial” ven sus posibilidades de prolongar sus estudios en una escuela secundaria reducidas a la nada.

$3^{\circ}$ ) Coincide el Magistrado discrepante con la mayoría en que a los Estados, dentro de su margen de apreciación en la esfera educativa, no se les puede prohibir que establezcan diferentes tipos de escuela para los niños con dificultades o que implementen programas educativos especiales que respondan a tales necesidades. Incluso añade: los Estados deben tomar en consideración a los alumnos que, por causa de especiales circunstancias (culturales lingüísticas o de otro tipo), requieran una forma específica de educación. Los Estados deben adoptar medidas positivas para compensar sus dificultades y proporcionarles medios para alcanzar un currículo normal.

Sin embargo, concluye Cabral, volviendo el argumento de la mayoría del revés, tales medidas nunca pueden conducir a que las dificultades se incrementen a consecuencia de que los alumnos sean ubicados en una escuela para niños con discapacidades para el aprendizaje. Recuerda el magistrado la doctrina del caso Thlimmenos v. Grecia (6 de abril de 2.000), en la que el Tribunal sostuvo que no sólo se discrimina cuando se trata de modo diferente a personas que están en análogas situaciones sin que concurra una justificación objetiva y razonable (discriminación "negativa"), sino también cuando "los Estados no tratan de modo diferente a personas cuyas situaciones son significativamente diferentes, sin una justificación objetiva y razonable” (discriminación “positiva”). La situación de los demandantes requería la adopción de medidas diferenciadas, pero la que les proporcionó el Estado checo sirvió para agravar la distancia entre ellos y los alumnos de las escuelas ordinarias. Cabral advierte de que no le corresponde a él indicar qué tipos de medidas positivas requerían los demandantes, pero lo que es cierto es que su reclutamiento en 
escuelas especiales diseñadas para niños con discapacidades de aprendizaje no parece ser un medio apropiado para resolver las dificultades de los niños gitanos. Se trata de dos tipos de alumnos enteramente diferentes.

d) Comentario crítico de la Sentencia: ¿es la exhumación de la doctrina Plessy, "separados, pero iguales"?

Me resulta claramente más convincente la opinión discrepante del magistrado Cabral (o incluso la dubitativa del magistrado Costa ${ }^{35}$ ) que la mayoritaria. Aunque técnicamente me parece más precisa la invocación en este caso del concepto de discriminación indirecta que el más lábil y elástico de la discriminación por indiferenciación (planteada episódicamente en el caso Thlimmenos, ya mencionado). Ciertamente, la discriminación indirecta no había sido apreciada por el Tribunal en relación con la prohibición de discriminación, mientras sí contaba con ese antecedente la consideración de que tratar jurídicamente de modo igual a los que de hecho están en una situación desigual (los niños con dificultades de aprendizaje y los niños gitanos) es también discriminatorio.

En cualquier caso, el Tribunal se niega a innovar en el asunto Ostrava, aunque habría sido una ocasión perfecta para ello. Todos las Sentencias anteriores examinaban discriminaciones directas (bastante "gruesas" por lo demás). Ahora tenía ante sí, por primera vez, un asunto de discriminación indirecta.

Como es sabido, se produce una discriminación indirecta cuando la aplicación de un criterio de diferenciación jurídico en principio neutro (en este caso, sería la capacidad intelectual de los niños en relación con el acceso a un tipo u otro de escuela) o no "sospechoso" (es decir, no basado en la raza) produce un resultado significativamente negativo o perjudicial respecto de la minoría racial en desventaja (en este caso, la segregación de la gran mayoría de los niños gitanos) en comparación con el grupo social mayoritario. Por eso se las llama también "discriminaciones de impacto" (frente a las discriminaciones de trato o directas). El caso Ostrava es una patente discriminación indirecta o de impacto.

El concepto de discriminación indirecta es una creación del Tribunal Supremo Federal en la Sentencia Griggs versus Duke Power Company, de 8 de marzo de 1.971 (ponente: Burger, Presidente del Tribunal a la sazón). Se debatía en este caso si era conforme a la Constitución la práctica empresarial de una compañía de electricidad de Carolina del Norte de exigir para la contratación y/o la promoción haber completado los estudios secundarios y/o realizar dos test de inteligencia general, lo cual en la práctica

${ }^{35}$ Aunque no coincido con él en el importante valor que, como la mayoría, asigna al carácter "neutro” desde el punto de vista racial de la diferencia jurídica de trato (la distinta capacidad intelectual de los niños), porque precisamente las discriminaciones indirectas se caracterizan porque el tertium comparationis es, prima facie, neutro o no sospechoso desde el punto de vista racial. Lo decisivo es el impacto de esta diferenciación, no el criterio en que se funda. Ni tampoco creo que otorgar el amparo en este asunto hubiera transformado la prohibición de discriminación en el acceso escolar en un derecho prestacional. El Tribunal no puede obligar al Estado a gastar una determinada cantidad de dinero en educación suficiente según su criterio, ni a hacerlo de una determinada manera, configurando un sistema educativo concreto, pero sí puede (y debe) impedir al Estado una organización que segregue a los alumnos desde su más temprana infancia por su origen racial o étnico por contraria al sistema del Convenio de Roma. Nuevamente aprecio una gramática conceptual deficiente en materia de igualdad y prohibición de discriminación. 
perjudicaba a la comunidad negra. El Tribunal observó que estas medidas no tenían que ver con un mejor desempeño del trabajo y, con carácter general, sostuvo que prácticas como esas, "incluso aunque fueran neutrales en su intención” (y no racistas), no pueden mantenerse "si sirven para ‘congelar' el statu quo de anteriores prácticas discriminatorias en el empleo". Hay que mirar "a las consecuencias” de la política empresarial y "no sólo a su intención". De modo que si una medida sirve en la práctica para excluir a los negros y no puede demostrarse su utilidad, debe prohibirse. Salvadas las distancias, el asunto Griggs tiene significativos puntos en común con el caso Ostrava. En ambos casos la clave del caso gravita en torno a un test en apariencia neutral (o no discriminatorio por razón de la raza), pero que, de hecho, viene a perjudicar sensiblemente a una minoría racial en particular (en un caso impidiendo el acceso al trabajo o su promoción, en otro, el acceso a una educación de calidad o, al menos, "normal”). En ambos casos parece irrelevante la intención discriminatoria (que es un argumento central de la mayoría del Tribunal Europeo, discutiblemente, además, porque, insisto, el criterio decisivo para apreciar una discriminación indirecta no es la intención de quien establece las diferencia de trato, sino el resultado de ésta).

Pero hay un punto crucial de distinción que conduce a que los fallos sean diametralmente opuestos: en el caso Griggs se da un gran valor a las estadísticas que miden el "impacto" diferenciador perjudicial para la minoría en comparación con el grupo social mayoritario (así, se recuerda que en la empresa trabajaban 95 empleados, sólo 14 de ellos negros, concentrados en un departamento en el que cobraban menos que el resto y del que muy difícilmente podían salir, y en la nota a pie de página sexta se constata que en Carolina del Norte en 1.960 mientras que el 34\% de los hombres blancos tenían estudios secundarios, sólo el 12\% de negros lo habían alcanzado; y mientras que el 58\% de los hombres blancos superaban los test, tan sólo el 6\% de los negros lo conseguían), mientras que, por el contrario, el Tribunal Europeo de Derechos Humanos se niega a conceder valor alguno a las estadísticas. De este modo es imposible reconocer discriminación indirecta alguna, porque precisamente los datos estadísticos son los únicos que pueden reflejar, como una fotografía, la eventual discriminación (esto es, el trato jurídico diferente y perjudicial para la minoría). El Tribunal Europeo invoca aquí como antecedente para invalidar los datos estadísticos la criticable doctrina (en los términos que he venido exponiendo) que acuñó en el asunto Jordan contra Reino Unido, de 4 de agosto de 2.001. Este caso versaba sobre el homicidio de un irlandés católico por fuerzas de seguridad británicas en Irlanda del Norte. El Tribunal sí encontró violación del art. 2 del Convenio (porque las autoridades británicas no investigaron efectivamente las circunstancias de la muerte), pero, seguramente por no herir la susceptibilidad de los británicos o por no alargar más la Sentencia, concluyó, un tanto lateralmente y sin mayor cuidado, la doctrina que más tarde cita en el caso Ostrava: "la estadística no puede por sí misma calificar una práctica como discriminatoria en los términos del art. 14”36. Esta tesis, que, más

\footnotetext{
${ }^{36}$ En el asunto Jordan, observa que "hay pruebas estadísticas" de que los católicos y nacionalistas reciben peor trato policial en Irlanda del Norte y de que son más disparados por la policía, pero no ha encontrado pruebas de que los homicidios resultantes impliquen un uso ilegal o excesivo de la fuerza por parte de los miembros de las fuerzas de seguridad y, por tanto, no habría lesión del art. 14 en relación con el art. 2.
} 
o menos ${ }^{37}$, puede tener cierto sentido en el caso Jordan en la medida en que ya se había condenado a las autoridades británicas por violación del art. 2, es profundamente perturbadora en su aplicación al caso Ostrava, porque impide de raíz al Tribunal apreciar la discriminación de impacto existente.

En resumidas cuentas, al Tribunal Europeo no le ha parecido discriminatoria una medida que tiene como resultado que la mayoría de niños gitanos de un país acaben en guettos educativos especiales, en los que conviven, además, con niños con serias discapacidades para el aprendizaje. No importa que se trate de una práctica segregacionista especialmente grave por los sujetos que la padecen, los niños, y por el objeto al que se refiere, la educación (con el agravante de que es la primaria). $\mathrm{Y}$ encima, como se ha puesto de relieve ${ }^{38}$, al no reconocer la discriminación estructural en el caso Ostrava, el Tribunal ha elegido "echar sobre las espaldas de los padres" (iletrados la mayoría) la carga de impugnar el sistema, sin tener en cuenta el consentimiento apenas informado de éstos. Evidentemente, tampoco otorga ningún peso el Tribunal al hecho de la persecución racista que sufren muchos niños gitanos en las escuelas ordinarias, lo que motiva en no pocos casos la decisión de sus padres a favor de las escuelas especiales. El caso Ostrava parece, pues, exhumar la ominosa doctrina Plessy "separados pero iguales"39.

El concepto de discriminación indirecta ha sido recibido (curiosamente, casi siempre primero judicial y más tarde normativamente) en la mayoría de los Estados europeos (en España a partir de la Sentencia del Tribunal Constitucional 145/1.991) y en la Unión Europea y ha sido impulsado recientemente por la Directiva 2000/43 CEE, ya citada. La Directiva entiende por igualdad de trato "la ausencia de toda discriminación, tanto directa como indirecta, basada en el origen racial o étnico” (art. 2.1). Existirá discriminación directa “cuando, por motivos de origen racial o étnico, una persona sea tratada de manera menos favorable de lo que sea, haya sido o vaya a ser tratada otra en situación comparable” (art. 2.2.a). Se producirá una discriminación indirecta “cuando una disposición, criterio o práctica aparentemente neutros sitúe a personas

${ }^{37}$ De nuevo estamos en presencia de la aproximación race-blind escasamente garantista de la prohibición de discriminación étnica o racial.

${ }^{38}$ Por Morag Goodwin: “D.H. and Others v. Czech Republic: A Major Set-Back for the Development of Non-Discrimination Norms in Europe”, German Law Journal, vol. 7, n. 4, 1 abril de 2.006.

${ }^{39}$ Como es fama, el Tribunal Supremo federal de Estado Unidos dictó en 1896 la Sentencia Plessy versus Ferguson, que consagró la regla "separados pero iguales" y decidió que una ley que permite la segregación racial bajo condiciones separadas pero iguales no viola la garantía constitucional de la protección igualitaria de las leyes. Se trataba de una ley de Louisiana que segregaba racialmente a los pasajeros de los ferrocarriles. El Tribunal sostuvo que la mera distinción legal entre blancos y negros no destruye la igualdad ni convierte a una en sierva de la otra y que la enmienda decimocuarta no pretende una igualdad social distinta; las leyes que imponen la separación -explicó- no implican establecer que una raza es superior o inferior a la otra; simplemente son actos del poder de Policía de un Estado (¿hay aquí un intento de argumentación "técnica” o "neutral”, y un subrayado de la falta de intención de discriminar, como en el caso Ostrava?) Hubo que esperar hasta 1,954, al caso Brown c/ Board of Education para que la mayoría, basándose en el voto disidente del juez Harlan en el caso Plessy, abandonara definitivamente la regla segregacionista. El Tribunal afirmó que "separar a unos niños de otros, de edad y calificaciones semejantes sólo a causa de su raza, genera un sentimiento de inferioridad acerca de su condición en la comunidad, sentimiento que puede afectar a sus corazones y sus mentes de un modo que probablemente nunca podrá ser reparado”. Creo que estas palabras son perfectamente aplicables al caso Ostrava. 
de un origen racial o étnico concreto en desventaja particular con respecto a otras personas, salvo que dicha disposición, criterio o práctica pueda justificarse objetivamente con una finalidad legítima y salvo que los medios para la consecución de esta finalidad sean adecuados y necesarios” (art. 2.2.b). Posiblemente, la finalidad perseguida con las escuelas especiales en la República Checa era legítima (atender a la diversa capacidad intelectual de los alumnos), pero es dudoso que los medios elegidos (esa concreta organización de la enseñanza) sean los adecuados, ya que el resultado es que la mayoría de los niños gitanos no pueden acceder a una educación básica ordinaria. Como acertadamente sostiene el magistrado Cabral, hay que diferenciar a los alumnos, sí, pero para concederles a todos ellos las mismas oportunidades de acceso a la educación y la cultura, y no precisamente para lo contrario, esto es, para segregar y dirigir a los miembros de minorías raciales a un camino hacia ninguna parte, como es lo que sucede aquí. En cualquier caso, en todos los países donde se aplica el concepto de discriminación indirecta, los datos estadísticos se utilizan necesariamente como prueba de ese impacto perjudicial sobre la minoría racial ${ }^{40}$. La decisión del Tribunal Europeo de Derechos Humanos, que precisamente perjudica a la minoría racial más discriminada en Europa, la comunidad gitana, es, además de todo lo dicho, poco afortunada por su extraña singularidad en el ámbito europeo.

\section{CONCLUSIÓN: LA DISCRIMINACIÓN RACIAL, UN DERECHO RECONOCIDO ESCASAMENTE Y CON RETROCESOS POR EL TRIBUNAL EUROPEO DE DERECHOS HUMANOS}

En definitiva, el caso Ostrava significa un enorme paso atrás en el desarrollo de una jurisprudencia sobre discriminación racial por parte del Tribunal de Estrasburgo a la altura del tiempo actual. Al negarse a conceder valor a los datos estadísticos (es decir, a la realidad), es “como si David se hubiera plantado ante Goliat con sus manos atadas a la espalda: esto no hace la victoria imposible, pero la dificulta mucho ${ }^{41 \text { ", }}$ El Tribunal tenía ante sí una práctica segregacionista de la minoría gitana en un ámbito social especialmente sensible, la escuela, que afectaba no sólo a la República Checa, sino a otros países del Este ${ }^{42}$, es decir, una discriminación estructural, y, sin embargo, careció de la audacia (y del background conceptual) para ponerle freno.

Ciertamente, el pedigrí jurisprudencial del Tribunal sobre discriminación en general y la racial en particular tampoco constituía un sólido antecedente, ya que,

\footnotetext{
${ }^{40}$ En España, desde la Sentencia del Tribunal Constitucional 128/1.987 (fundamento jurídico décimo) en la que ya se traen datos estadísticos de la Encuesta de Población Activa. También el Tribunal de Justicia de la Unión los utiliza ordinariamente.

${ }^{41}$ G. Goodwin, ob.cit., p. 3.

42 Aunque mejor, la situación en España tampoco es como para felicitarse. Según un estudio sobre "El acceso del alumnado gitano a la enseñanza secundaria” de la Fundación Secretariado Gitano (ver: Gitanos. Pensamiento y Cultura, n ${ }^{\circ}$ 34-35, 2.006, pp. 27-50), el 70\% de los mayores de 16 años no finaliza los estudios primarios; el 80\% de los pocos alumnos gitanos que inician la E.S.O. no la concluyen, etc.) El Informe del Observatorio Europeo del Racismo y la Xenofobia sobre "Los gitanos y la educación pública”, de 4 de mayo de 2.006, constata que "todos los sistemas educativos europeos están fallando a los alumnos gitanos y, como consecuencia de ello, éstos tienden a abandonar la escuela de forma anticipada”; así que "queda mucho por hacer, sobre todo en lo que respecta a la segregación, que sigue siendo en todas sus formas el principal escollo para los niños roma y traveller en el sistema educativo”.
} 
como hemos visto, la protección otorgada desde Estrasburgo ha sido, por lo común, de baja intensidad, muy desigual y sin un marco conceptual convincente. En algunos escenarios de conflicto, como el de la violencia racista por agentes públicos, el Tribunal, tras la Sentencia Nachova, sí se ha había puesto serio en la aplicación del art. 14 del Convenio, abandonando su lectura race-blind habitual. Pero a este esperanzador avance le sigue, tan sólo unos meses después, el monumental retroceso del caso Ostrava. ¿Cómo fallará el Tribunal en el siguiente caso? ¿Cuál es su mensaje de protección para las minorías raciales y/o étnicas después de más de cincuenta años de existencia? 